\title{
Pesquisa de sífilis congénita al momento del parto: ¿Suero materno o sangre de cordón?
}

\author{
Fernando Abarzúa C., Cristián Belmar J., Alonso Rioseco R., Jacqueline Parada B., \\ Teresa Quiroga G. y Patricia García C.
}

\section{Diagnosis of congenital syphilis at delivery: Maternal serum or cord blood?}

Congenital syphilis (CS) is an important health problem in Chile, with a rate of 0.25/1,000 live newborn (NB) during year 2004. In 2000, the Chilean Ministry of Public Health recommended to perform a screening in cord blood at the moment of delivery. Instead, the Centers for Disease Control and Prevention guidelines recommend the screening in maternal serum since cord blood has up to $5 \%$ of false (-) versus $0.5 \%$ of maternal serum, both with respect to the NB serum. Objective: Maternal serum and NB cord blood were studied during one year to determine the best screening method at delivery. Methods: RPR was performed and positive results were confirmed by treponemic test (immunochromatographyDetermine ${ }^{\circledR}$, ELISA Captia ${ }^{\circledR}$, Ig and IgM, and MHA-Tp). Serologically confirmed patients were evaluated by the specialist to define CS cases. Results: Between June 1999 and August 2000 2,741 binomies were studied; of these, 37 (1.3\%) were RPR reactive and 2.704 were non-reactive. In 11 of the 37 reactive cases, mother and NB were RPR reactive (Group I), in 9 cases the NB was RPR reactive and the mother was non-reactive (Group II), and the other 17 were NB non-reactive and mother reactive (Group III). In group I, 7/11 (64\%) were true (+)s and 4/11(36\%) false (+)s of RPR. In group II, 9/9 (100\%) corresponded to false (+)s of RPR in cord blood, and in group III, 11/17 (65\%) corresponded to false (+)s of RPR in maternal blood but 6/17 (35\%) were found to be cases of syphilis during pregnancy. Three of them were not treated opportunely and were designed as CS. In total 9 NB corresponded to CS (6 in group I and 3 in group III). If the screening had been performed only in cord blood, three NB with CS would have not been diagnosed. Conclusion: Even when maternal serum has a high rate of false $(+) s$, it has better sensitivity than cord blood for the diagnosis of CS, thus it is suggested to perform the screening at delivery with maternal serum instead of cord blood samples.

Key words: Congenital syphilis, pregnancy, cord blood sampling.

Palabras clave: sífilis congénita, embarazo, sangre de cordón.

\section{Introducción}

$\mathrm{L}$ a sífilis es una enfermedad sistémica causada por Treponema pallidum, siendo la infección natural exclusiva del ser humano. La vía principal de transmisión es el contacto sexual. Sin embargo, la vía transplacentaria también es importante; T. pallidun puede pasar al feto en cualquier momento de la gestación, y así producirse una sífilis congénita (SC).

Sífilis congénita, según la definición del Ministerio de Salud de Chile, es toda infección producida por $T$. pallidum adquirida por el feto por vía transplacentaria durante el período de gestación desde una madre con sífilis no tratada o inadecuadamente tratada ${ }^{1}$. Puede manifestarse ya en la vida intrauterina (aborto, hidrops fetal no inmune, muerte fetal intrauterina) o ser clínicamente inaparente al momento del parto (60\% de los casos) $)^{2}$, evolucionando durante la infancia con grave compromiso y secuelas si no se diagnostica y trata oportunamente.

La SC es un problema antiguo en Chile, con tasas de 0,14/1.000 recién nacidos vivos (RNV), en 1999, y de 0,25/1.000 RNV en 2004. A pesar de todas las políticas de prevención, se reportaron alrededor de 50 casos anuales de SC en el período 2000-2005³. El Ministerio de Salud, de acuerdo al plan de la Organización Panamericana de la Salud (OPS) de erradicar la SC, se ha propuesto reducir la incidencia de la enfermedad por medio de la detección, diagnóstico precoz y tratamiento oportuno a las mujeres embarazadas infectadas (MINSAL, 2005) ${ }^{3}$.

Muchas veces el diagnóstico serológico en el recién nacido $(\mathrm{RN})$ está dificultado por el paso de anticuerpos tipo IgG maternos (treponémicos y no treponémicos) al feto, haciendo más difícil la interpretación de la serología en los primeros meses de vida. Se ha
Pontificia Universidad Católica de Chile, Santiago de Chile Facultad de Medicina Departamento de Obstetricia y Ginecología (FAC, CBJ, ARR) Departamento de Laboratorios Clínicos (JPB, TQG, PGC)

Recibido: 26 de octubre 2007 Aceptado: 10 de marzo 2008

Correspondencia a: Fernando Abarzúa Camus fabarzua@med.puc.cl 
sugerido que la utilización de pruebas treponémicas que detecten IgM, podría ser de utilidad ${ }^{4}$; sin embargo, en nuestra experiencia un resultado negativo de IgM en suero de RN, no descarta la posibilidad de SC 5 .

La identificación de los RNs con riesgo de SC es dependiente de la realización de la prueba serológica a las madres durante el embarazo y parto, ya que la mayoría de ellas son asintomáticas. Por esto se realiza tamizaje a todas las mujeres embarazadas al ingreso a control prenatal, repitiéndose en el tercer trimestre del embarazo y al momento del parto ${ }^{1,6,13}$. Algunas madres en alto riesgo de adquirir sífilis pudiesen no tener buen control prenatal y la detección estará, en estos casos, limitada al momento del parto.

Por ello, adquiere gran importancia determinar cuál es la mejor muestra para pesquisar los RNs con riesgo de SC.

Existe evidencia que las pruebas no treponémicas, tanto en sangre materna como en cordón, tienen alta tasa de falsos positivos; no obstante, la tasa de falsos negativos (casos de SC no pesquisada en RNs con riesgo) en suero materno sería de $0,5 \%$ versus hasta $5,0 \%$ en la sangre de cordón $^{7-10}$.

Basado en este concepto, el Centro de Control y Prevención de Enfermedades-(CDC), de Atlanta, E.U.A., modificó su normativa en relación al tamizaje en el momento del parto, y desde 1998 recomienda realizar pesquisa en suero materno y no en sangre de cordón ${ }^{6}$.

En nuestro medio no existe experiencia que evalúe esta modificación, y la norma MINSAL del año 2000, vigente al momento de la realización de este estudio mantenía el tamizaje en sangre de cordón ${ }^{1}$.

Por ello, y con el objetivo de determinar cuál es la mejor muestra para pesquisar, al momento del parto, los RNs con riesgo de SC, se estudiaron con pruebas treponémicas y no treponémicas, muestras de suero materno y sangre de cordón de los RNs en binomios que se atendieron en nuestro centro durante un año, en el período 1999-2000.

\section{Pacientes y Métodos}

En el período comprendido entre junio de 1999 y agosto de 2000 se estudiaron, en forma prospectiva, las muestras de suero materno y sangre de cordón de todos los binomios madre-RN que se atendieron en la Maternidad del Hospital Clínico de la Pontificia Universidad Católica de Chile.

Se realizó como tamizaje la prueba no treponémica RPR (Rapid Plasma Reagin) y de resultar positiva la muestra materna, del RN o ambas, se efectuaron pruebas confirmatorias treponémicas validadas previamen- te $^{9}$ : inmunocromatográfico Determine ${ }^{\circledR}$, ELISA Captia ${ }^{\circledR}$ IgG e IgM y microhemaglutinación-Tp. Todos los pacientes confirmados mediante pruebas treponémicas fueron evaluados por el especialista para diagnosticar los casos de SC, de acuerdo a las definiciones de enfermedad confirmada y sospechosa del $\mathrm{CDC}^{3}$ y del MINSAL-Chile ${ }^{1}$ y para decidir el tratamiento antimicrobiano.

Se registraron los antecedentes maternos en relación a pruebas treponémicas y no treponémicas realizadas durante el embarazo, tratamiento anteparto efectuado y seguimiento materno (serológico) y fetal (clínico-ecográfico).

Los binomios en que la pesquisa resultó positiva se dividieron en tres grupos (Figura 1):

Grupo I: Prueba no treponémica reactiva (R) en suero materno y sangre de cordón.

Grupo II: Prueba no treponémica reactiva (R) en sangre de cordón y no reactiva (NR) en suero materno.

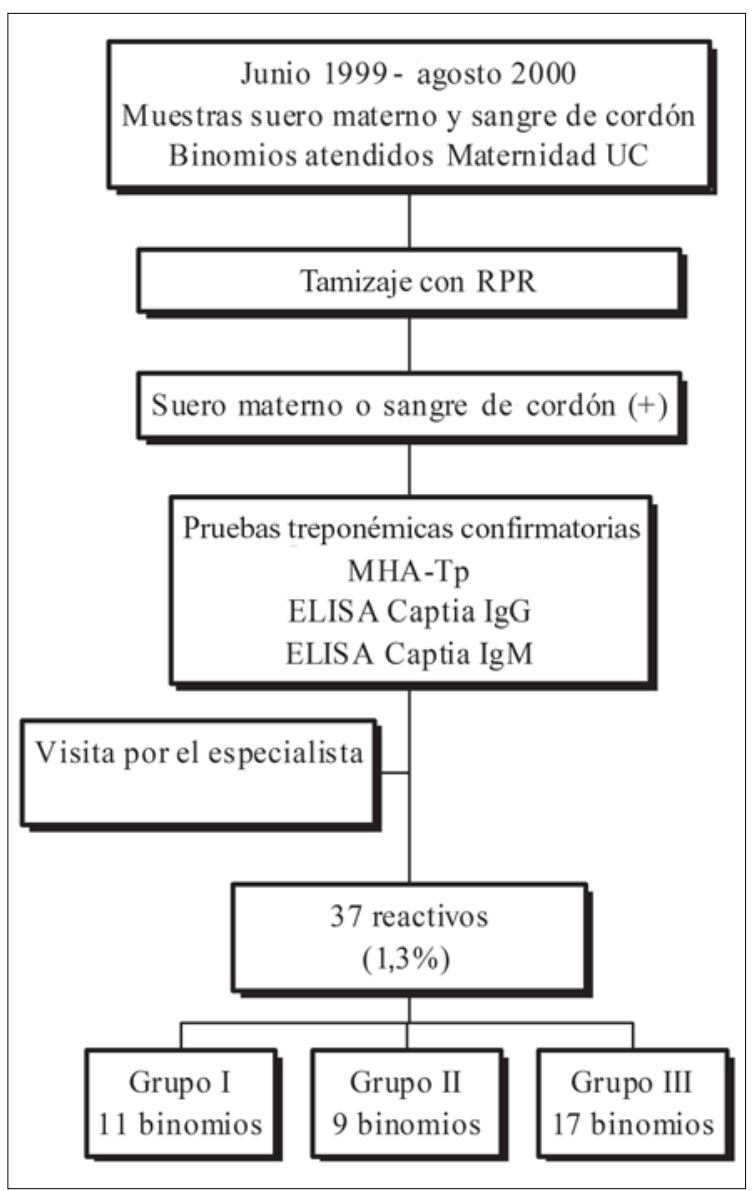

Figura 1. Descripción de los pacientes que ingresaron al estudio. RPR: Rapid Plasma Reagin. MHA-Tp: microhemaglutinación Treponema pallidum. 
Grupo III: Prueba no treponémica reactiva (R) en suero materno y no reactiva (NR) en sangre de cordón.

En los tres grupos se analizaron los antecedentes maternos en relación al momento del diagnóstico, tipo de tratamiento si existió, seguimiento y evaluación del $\mathrm{RN}$ para decidir su tratamiento.

\section{Resultados}

En el período de estudio hubo un total de 3.314 partos. De ellos, se contó con la muestra del binomio en 2.741 casos (82\%). En el 17\% restante, sólo se realizó muestra de cordón.

De los 2.741 binomios, 2.704 resultaron no reactivos (99\%), y 37 (1,3\%), reactivos. Los 37 binomios reactivos se dividieron en los tres grupos ya definidos, según se detalla a continuación: grupo I: 11 binomios, grupo II: 9 binomios y grupo III: 17 binomios (Figura 2).

En el grupo I hubo 7/11 (64\%) verdaderos positivos para sífilis materna. De ellos, hubo 6 recién nacidos que requirieron tratamiento por SC probable (Tabla 1). Los cuatro restantes (36\%), correspondieron a falsos positivos de la prueba no treponémica.

En el grupo II, los 9 pacientes en que sólo la sangre de cordón fue reactiva, resultaron falsos positivos de la prueba no treponémica. La cuantificación del título de RPR en todas ellos fue reactivo sin diluir (1:1). Todas las muestras de suero de los recién nacidos resultaron no reactivas (Tabla 2).

En el grupo III hubo 11/17 (65\%) de falsos positivos del RPR en sangre materna. De los 11, sólo en uno (9\%) el RPR de suero del RN fue también reactivo con un título 1:1 (reactivo sin diluir). Los seis pacientes restantes (35\%) correspondieron a sífilis materna. De ellos, tres RNs requirieron tratamiento por SC probable. Los tres casos correspondieron a mujeres embarazadas, en que el diagnóstico de sífilis, sólo se hizo al momento del parto (Tabla 3). Estos tres casos, que constituyen 33\% (3/9) de los RN que requirieron tratamiento, sólo se diagnosticaron mediante la muestra de sangre materna.

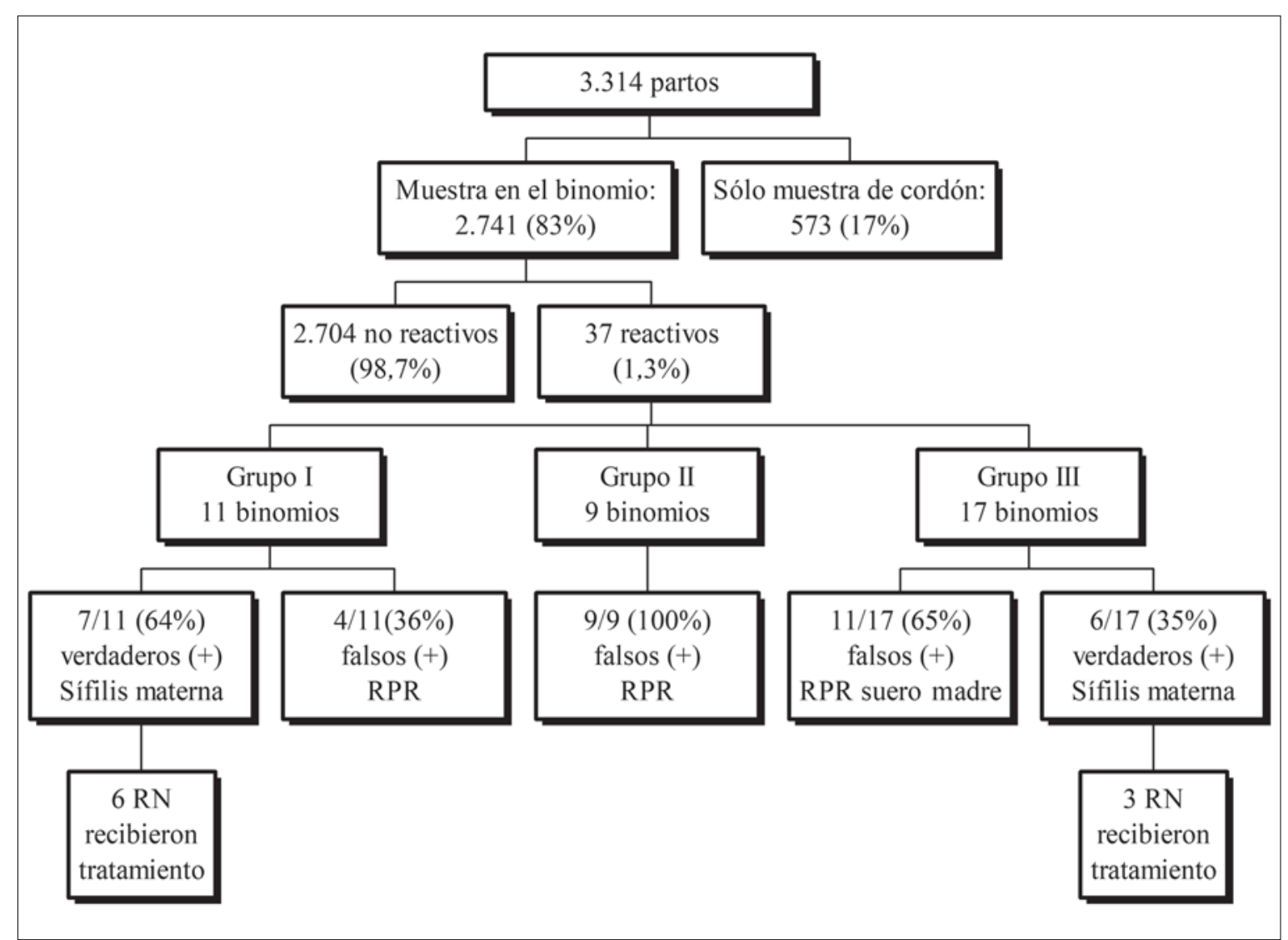

Figura 2. Resultados de las pruebas no treponémicas y treponémicas en los binomios. 


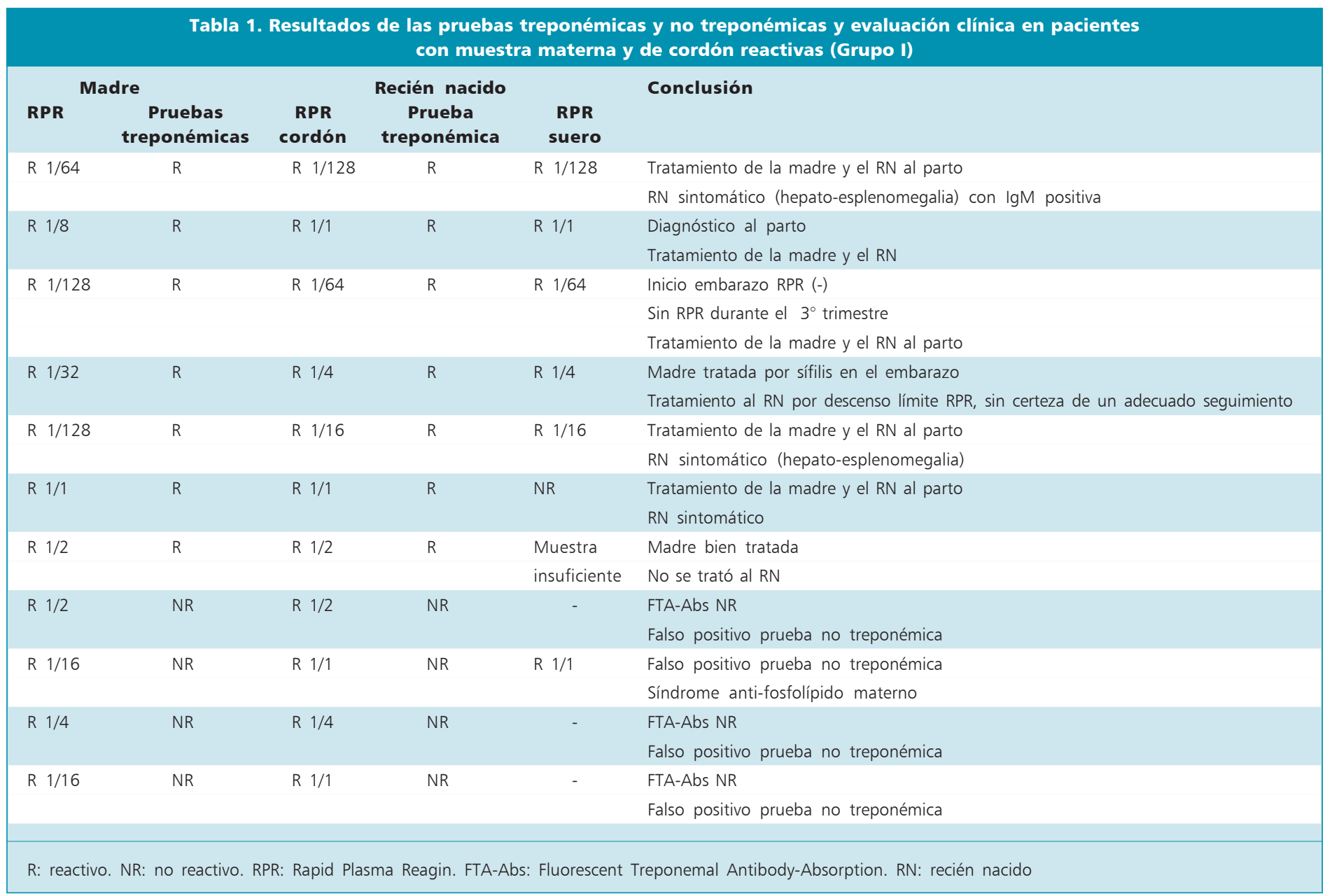

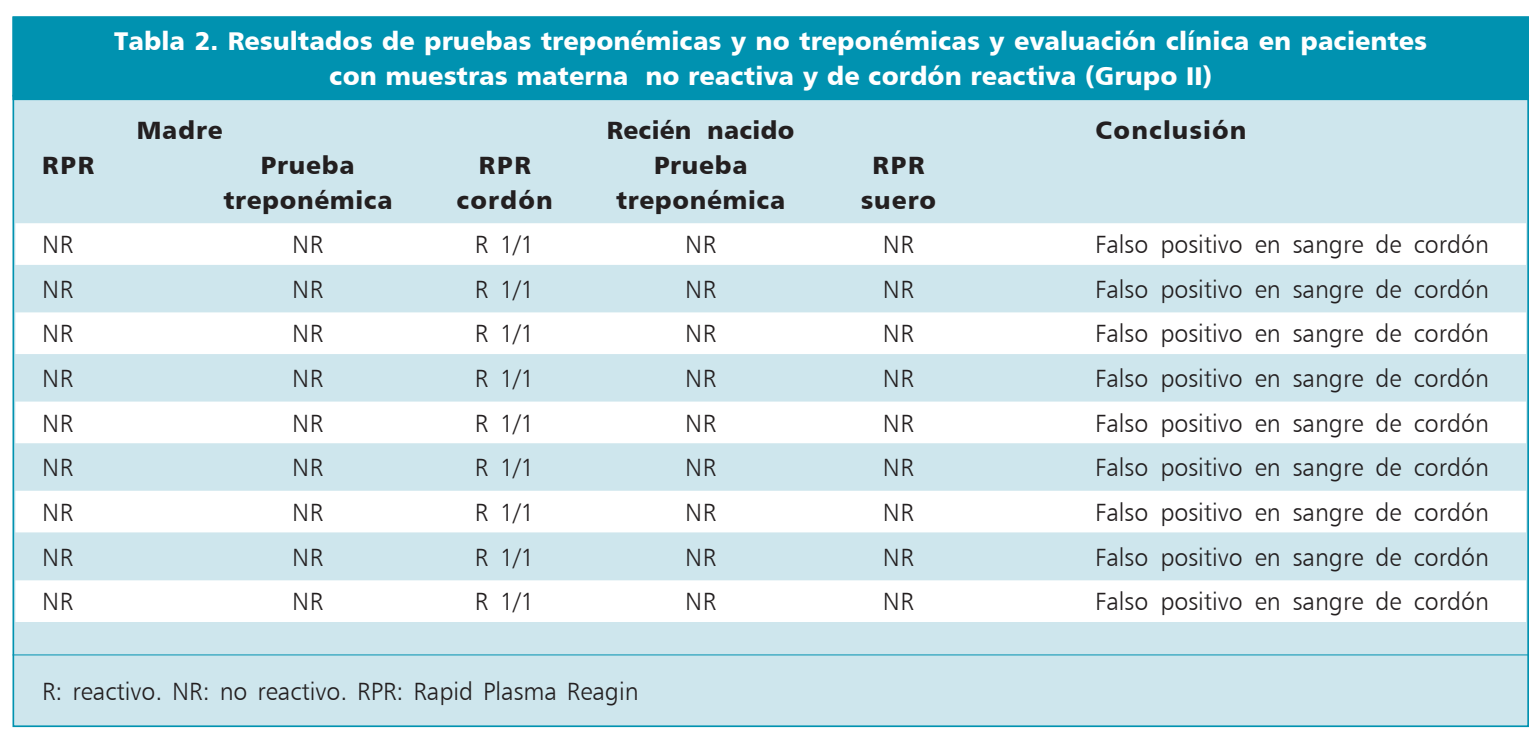




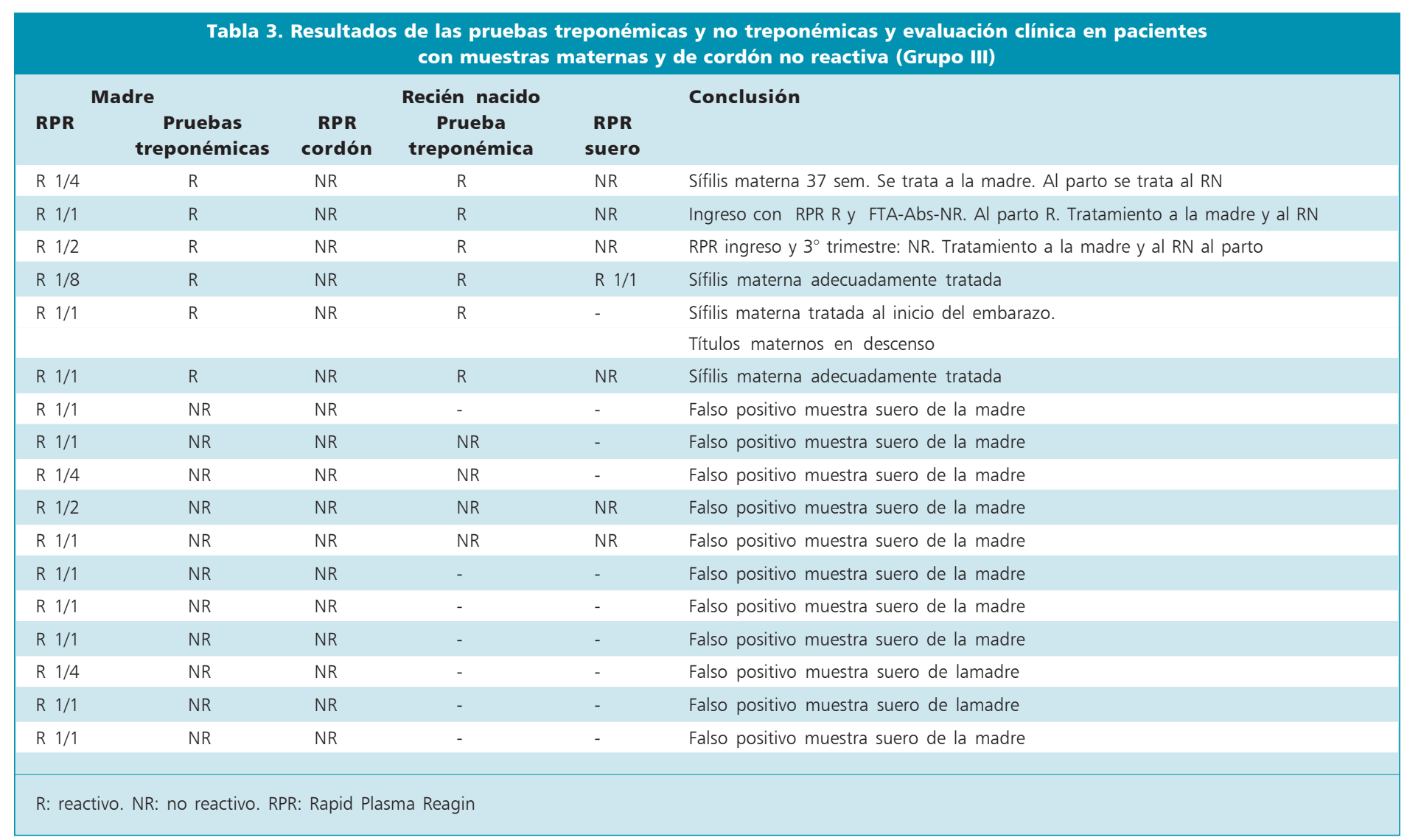

El análisis general de los falsos positivos de la prueba no treponémica, en relación a los 37 binomios, fue de $65 \%$ (24/37), que se divide en: ambas muestras reactivas: $17 \%(4 / 24)$; sólo sangre de cordón reactiva: $38 \%$ (9/24) y sólo suero materno reactivo: 45\% (11/24).

Hubo 20 binomios con RPR reactivo en sangre de cordón (independiente del RPR de suero materno), de ellos, 13 fueron falsos positivos (65\%). A su vez, hubo 28 con RPR reactivo en suero materno (independiente del resultado en el cordón), de éstos, 15 correspondieron a falsos positivos (53\%).

Sin embargo, la tasa de falsos positivos de las pruebas no treponémicas en el total de partos estudiados fue de sólo $1 \%$.

La tasa de falsos negativos de la prueba no treponémica, según tipo de muestra, fue de $35 \%$ en sangre de cordón (6/17), todos con sangre materna reactiva. No hubo falsos negativos en la muestra de sangre materna.

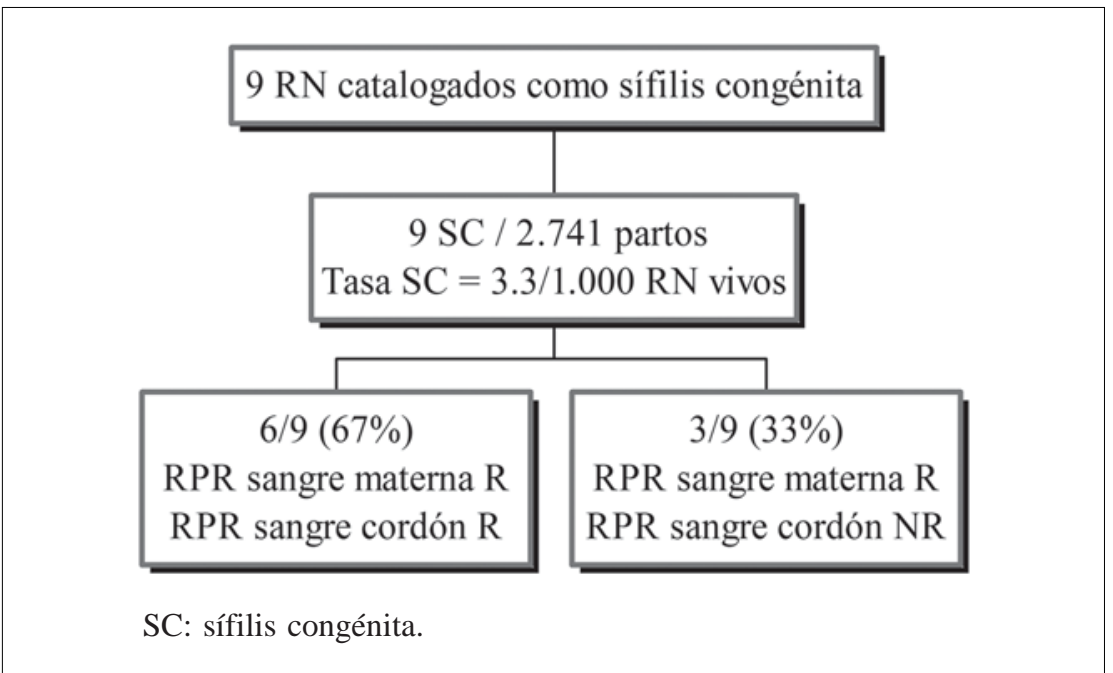

Figura 3. Resultados de las pruebas no treponémicas según el tipo de muestra en que se realiza la pesquisa en los 9 casos catalogados como sífilis congénita. 


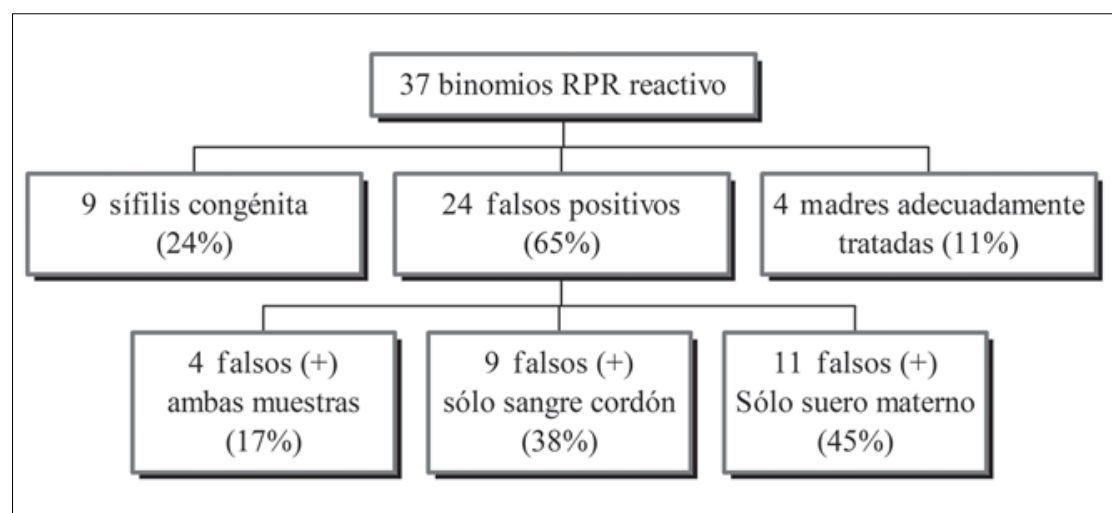

Figura 4. Análisis de los falsos positivos de las pruebas no treponémicas según el tipo de muestra utilizada para la pesquisa en los 37 binomios reactivos. den en que la tasa de falsos negativos es diferente según el tipo de muestra analizada, siendo más alta la tasa en muestra de cordón que en suero materno (5 versus $0,5 \%$ ), con el riesgo de no pesquisar casos de sífilis materna y de SC si se opta por tomar sólo la muestra de cordón.

Esta consideración llevó al CDC a modificar su recomendación en el año 1998, indicando que la muestra más adecuada para tamizaje en el momento del parto es el suero materno y no la sangre de cordón ${ }^{6}$. Este cambio no se vio reflejado en la normativa del MINSALChile en el año 2000, la que estableció la sangre de cordón para efectuar el tamizaje al momento del parto. No obstante, se indicaba que aquellas mujeres embarazadas que tenían sólo una prueba serológica en el control de embarazo, se les tomase además, una muestra de suero al momento del parto, lo que parecería contradictorio con la recomendación anterior, (estaría considerando la posibilidad que una muestra materna pudiese pesquisar un caso en que la muestra de cordón fuese no reactiva). Por ello nos pareció muy importante evaluar, en la población que se atendía en nuestro centro, medir el rendimiento, tanto del suero materno como de la sangre de cordón, para la pesquisa de los niños en riesgo de adquirir SC.

En nuestra experiencia, tres de los nueve RNs que requirieron tratamiento (33\%) no se hubiesen pesquisado, si sólo se hubiese realizado pesquisa en sangre de cordón, pues todas las madres tenían RPR no reactivos en el ingreso pre-natal, y en el tercer trimestre el resultado era no reactivo o no se había realizado. Por otra parte, todas ellas eran del grupo de "bajo riesgo”, por lo que, según la norma ministerial vigente en ese momento, no se les habría solicitado otra prueba de RPR alrededor de las 34 semanas.

Nuestro trabajo, junto a las demás experiencias extranjeras, apoya la utilidad del tamizaje en sangre materna al momento del parto. Por ello, a partir de estos resultados, en nuestro centro se realizó RPR tanto en la muestra en suero materno como en sangre de cordón al momento del parto, hasta que el MINSAL instruyó a todos los Servicios de cambiar la muestra para tamizaje en el parto ${ }^{12}$, mediante la Resolución 262 del 28 de abril del 2006. La actual normativa indica realizar cuatro tamizajes a las mujeres embarazadas: al primer control, a las 24 semanas, entre las 32 y 34 semanas y al momento de ingresar al parto.

A partir de ese momento, y en la actualidad, sólo se realiza la pesquisa con sangre materna. El costo adicional de los falsos positivos de la muestra materna tiene a nuestro juicio, un mínimo impacto como costo adicional, por la realización de una prueba treponémica confirmatoria, comparado con el beneficio de no presentar falsos negativos para SC en los RNs. 


\section{Resumen}

La sífilis congénita (SC) es un problema importante en Chile, con una tasa de 0,25/1.000 recién nacidos (RNs) vivos en el año 2004. En el año 2000, el Ministerio de Salud recomendaba como tamizaje al momento del parto una muestra de sangre de cordón. El Centro de Control y Prevención de Enfermedades, (CDC), Atlanta, E.U.A. recomendó, desde 1998, el tamizaje al parto con suero materno ya que respecto del suero del $\mathrm{RN}$, la sangre de cordón y el suero materno tienen respectivamente hasta 5 y 0,5\% de falsos negativos. Objetivo: Determinar el mejor tamizaje al momento del parto. Métodos: Se estudiaron muestras de suero materno y sangre de cordón de los RNs durante un año. Se realizó RPR y de ser positiva, pruebas treponémicas confirmatorias (imunocromatográfico Determine ${ }^{\circledR}$, ELISA Captia ${ }^{\circledR}$ IgG e IgM y microhemaglutinación). Todos los pacientes confirmados fueron vistos por el especialista para definir los casos de SC. Resultados: Entre junio de 1999 y agosto del 2000 se estudiaron 2.741 binomios madre-RN; de éstos 37/2.704 (1,3\%) fueron RPR reactivos. Once eran RPR reactivo en la madre y en el RN (Grupo I), 9 eran RPR reactivo en el RN y no reactivo en la madre (Grupo II) y 17 eran $\mathrm{RN}$ con RPR no reactivo y reactivo en la madre (Grupo III). En el Grupo I hubo 64\% (7/11) de verdaderos (+)s y 36\% (4/11) de falsos (+)s del RPR. En el Grupo II, 9/ 9 (100\%), correspondieron a falsos $(+)$ s del RPR en sangre de cordón y en el Grupo III, 11/17 (67\%) correspondieron a falsos (+)s del RPR en sangre materna pero hubo 6/17 (35\%) que correspondían a sífilis durante el embarazo y en tres de ellas no hubo tratamiento intra-embarazo, por lo que fueron catalogadas como SC y los RNs debieron ser tratados. En total hubo 9 RNs que correspondieron a SC (6 del grupo I y 3 del grupo III). Si sólo se hubiese realizado tamizaje en sangre de cordón, 3 RNs con SC no se hubiesen diagnosticado. Conclusión: Si bien el suero materno tiene una tasa de falsos (+)s alta, tiene mejor sensibilidad que la sangre de cordón para el diagnóstico de SC; por lo que se sugiere realizar el tamizaje al momento del parto con suero materno en vez de sangre de cordón.

\section{Referencias}

1.- República de Chile, Ministerio de Salud, Comisión Nacional del SIDA, Área ETS, Normas de Manejo y Tratamiento de Enfermedades de Transmisión Sexual 2000; 21-25.

2.- Glaser J H. Centers for Disease Control and Prevention Guidelines for Congenital Syphilis. J Pediatr 1996; 129: 488- 90.

3.- Ministerio de Salud de Chile. Boletín de Vigilancia en Salud Pública de Chile. El Vigía $\mathrm{N}^{\circ}$ 2. 2005; 9, 23: 49.

4.- Larsen S, Pope V, Johnson R, Kennedy E. Manual of Tests for Syphilis. $9^{\text {th }}$ Edition American Public Health Association, Washington DC, 1998, p: 1-361.

5.- Salazar A, Perret C, Chávez A, García P,
Millan Z, Goycolea M, et al. Evaluación de métodos para sífilis congénita. Rev Chil Infect 2000; 17: 289-96.

6.- Centers for Disease Control and Prevention. Guidelines for Treatment of Sexually Transmitted Diseases. MMWR Morbid Mortal Wkly Rep 1998; 47: 40-3.

7.- Farnes S W, Setness P A. Serologic tests for syphilis. Postgrad Med 1990; 87: 37-46.

8.- Chhabra R, Brion L, Castro M, Freundlich L, Glaser J. Comparison of maternal sera, cord blood, and neonatal sera for detecting presumptive congenital syphilis: relationship with maternal treatment. Pediatrics 1993; 91: 88-91.

9.- Rawstron S, Bromberg K. Comparison of maternal and newborn serologic tests for syphilis. Am J Dis Child 1991; 145: 1383-8.
10.- Stoll B. Congenital syphilis: Evaluation and management of neonates born to mothers with reactive serologic tests for syphilis. Pediatr Infect Dis J 1994; 13: 845-52.

11.- Brown S, Zaidi A, Larsen S, Reynolds G. Serological response to syphilis treatment. A new analysis of old data. JAMA 1985; 253: 1296-9.

12.- Ministerio de Salud de Chile. Modificación del texto de la norma general técnica $N^{\circ} 46$ sobre manejo y tratamiento de enfermedades de transmisión sexual. Resolución exenta $\mathrm{N}^{\circ}$ 262. MINSAL 2006.

13.- Centers for Disease Control and Prevention. Guidelines for treatment of sexually transmitted diseases. MMWR Morbid Mortal Wkly Rep 2006; 55: RR-11. 